\title{
Novel digital imaging techniques to assess the outcome in oral rehabilitation with dental implants: a narrative review
}

Benic, Goran I ; Elmasry, Moustafa ; Hämmerle, Christoph H F

\begin{abstract}
AIM: To examine the literature on novel digital imaging techniques for the assessment of outcomes in oral rehabilitation with dental implants. MATERIAL AND METHODS: An electronic search of Medline and Embase databases including studies published prior to 28th December 2014 was performed and supplemented by a manual search. A synthesis of the publications was presented describing the use of computed tomography (CT), magnetic resonance imaging (MRI), ultrasonography, optical scanning, spectrophotometry or optical coherence tomography (OCT) related to the outcome measures in implant therapy. RESULTS AND CONCLUSIONS: Most of the digital imaging techniques have not yet sufficiently been validated to be used for outcome measures in implant dentistry. In clinical research, cone beam CT (CBCT) is increasingly being used for 3D assessment of bone and soft tissue following augmentation procedures and implant placement. Currently, there are no effective methods for the reduction of artifacts around implants in CBCT. Optical scanning is being used for the 3D assessment of changes in the soft tissue contour. The combination of optical scan with pre-operative CBCT allows the determination of the implant position and its spatial relation to anatomical structures. Spectrophotometry is the method most commonly used to objectively assess the color match of reconstructions and peri-implant mucosa to natural dentition and gingiva. New optical imaging techniques may be considered possible approaches for monitoring peri-implant soft tissue health. MRI and ultrasonography appear promising non-ionizing radiation imaging modalities for the assessment of soft tissue and bone defect morphologies. Optical scanners and OCT may represent efficient clinical methods for accurate assessment of the misfit between the reconstructions and the implants.
\end{abstract}

DOI: https://doi.org/10.1111/clr.12616

Posted at the Zurich Open Repository and Archive, University of Zurich

ZORA URL: https://doi.org/10.5167/uzh-113470

Journal Article

Accepted Version

Originally published at:

Benic, Goran I; Elmasry, Moustafa; Hämmerle, Christoph H F (2015). Novel digital imaging techniques to assess the outcome in oral rehabilitation with dental implants: a narrative review. Clinical Oral Implants Research, 26 Suppl:86-96.

DOI: https://doi.org/10.1111/clr.12616 


\title{
Novel digital imaging techniques to assess the outcome in oral rehabilitation with dental implants: a narrative review
}

\author{
Goran I. Benic, Moustafa Elmasry, \\ Christoph H.F. Hämmerle
}

Clinic of Fixed and Removable Prosthodontics and Dental Material Science, Center of Dental Medicine, University of Zurich, Zurich, Switzerland

Address for correspondence: Dr. Goran I. Benic

Clinic of Fixed and Removable

Prosthodontics and Dental Material

Science

Center of Dental Medicine University of Zurich

Plattenstrasse 11

$\mathrm{CH}-8032$ Zurich

Tel: +41634 32 52;

Fax: +41446344305

E-mail: goran.benic@zzm.uzh.ch 


\section{Abstract}

Aim: To examine the literature on novel digital imaging techniques for the assessment of outcomes in oral rehabilitation with dental implants.

Material and methods: An electronic search of Medline and Embase databases including studies published prior to $28^{\text {th }}$ December 2014 was performed and supplemented by a manual search. A synthesis of the publications was presented describing the use of computed tomography (CT), magnetic resonance imaging (MRI), ultrasonography, optical scanning, spectrophotometry or optical coherence tomography (OCT) related to the outcome measures in implant therapy.

Results and conclusions: Most of the digital imaging techniques have not yet sufficiently been validated to be used for outcome measures in implant dentistry. In clinical research, cone beam CT (CBCT) is increasingly being used for 3D assessment of bone and soft tissue following augmentation procedures and implant placement. Currently, there are no effective methods for the reduction of artifacts around implants in CBCT. Optical scanning is being used for the 3D assessment of changes in the soft tissue contour. The combination of optical scan with preoperative CBCT allows the determination of the implant position and its spatial relation to anatomical structures. Spectrophotometry is the method most commonly used to objectively assess the color match of reconstructions and peri-implant mucosa to natural dentition and gingiva. New optical imaging techniques may be considered possible approaches for monitoring peri-implant soft tissue health. MRI and ultrasonography appear promising non-ionizing radiation imaging modalities for the assessment of soft tissue and bone defect morphologies. Optical scanners and OCT may represent efficient clinical methods for accurate assessment of the misfit between the reconstructions and the implants. 


\section{Introduction}

The placement of dental implants to replace missing teeth is a welldocumented therapy showing high long-term survival rates (Jung et al. 2012, Pjetursson et al. 2012a). These results have been reported for implants placed into native bone and for implants placed in conjunction with bone augmentation procedures (Benic et al. 2009, Jung et al. 2013a). As far as the success of implant therapy is concerned, the health of the peri-implant tissue and the functional aspects related to the implant-supported reconstruction are important parameters to be considered when assessing the outcome of implant therapy. Moreover, the visual appearance of the peri-implant soft tissue and of the reconstruction within the given dentition and the facial frame represents an important factor for clinical success in esthetic sites.

In recent review articles it was concluded that there is a lack of consensus regarding the definition of success for implant therapy and the choice of outcomes to measure implant success (Benic et al. 2012b, Cairo et al. 2012, Pjetursson et al. 2012b). Therefore, specific outcome domains have been proposed for clinical research including biological, technical, esthetic, and patient-centered parameters (Lang et al. 2012, Tonetti et al. 2012). In addition, the use of objective and reproducible assessments of outcomes was recommended to improve clinical research in this field. So far, assessments in human were typically done applying clinical examination techniques and conventional two-dimensional radiography.

In the past years, digital equipment including optical scanners, computed tomography, magnetic resonance imaging and spectrophotometry were introduced for imaging in implant dentistry. In combination with computer software these imaging methods allow precise and reproducible assessment of implant-related parameters such as the volume of peri-implant tissues, the implant position, the color of the mucosa and of the reconstruction, and the prosthetic fit.

Up to now, the information available in the scientific literature regarding these new digital imaging methods has not been scrutinized. The aim of the present narrative review was, therefore, to examine the literature on the novel digital imaging techniques for the assessment of outcomes in oral rehabilitation with dental implants. 


\section{Material \& Methods}

\section{Search strategy}

An electronic search of Medline (Pubmed) and Embase databases was performed including studies published prior to $28^{\text {th }}$ December 2014 . The search was limited to publications published in English.

The following search terms were used: („dental implants“ OR „dental implant“ OR „dental implantology“ OR „peri-implant“) AND („CT“ OR „computed tomography“ OR „MSCT“ OR „CBCT“ OR „Cone beam computed tomography“ OR „cone beam CT“ OR “digital volume tomography” OR “DVT” OR „ultrasound“ OR „sonography“ OR „ultrasonography“ OR „ultrasonic“ OR „ultrasonographic“ OR „magnetic resonance imaging“ OR „MRI“ OR „optical coherence tomography“ OR „optical scan“ OR „optical scanner“ OR „optical impression“ OR „intraoral scan“ OR „intraoral scanner“ OR “digital scan” OR „3D“ OR „three-dimensional“ OR „volume“ OR „volumetric“ OR „spectrophotometer“ OR „spectrophotometry“ OR „spectrophotometric“)

The electronic search was complemented by a manual search of reference lists of the included publications.

\section{Selection of studies}

Publications describing the use of computed tomography, ultrasonography, magnetic resonance imaging, optical coherence tomography, optical scanning, or spectrophotometry related to the assessment of outcome in implant therapy were included. The clinical studies were excluded, which reported exclusively on the use of digital imaging methods for treatment planning.

Two investigators independently performed the literature search including selection of titles, abstracts and full text publications. All titles obtained by the search were screened for meeting the selection criteria. If the title did not contain sufficient information for inclusion/exclusion, the abstract and, if needed, the full text was reviewed. The final selection of the publication was performed based on the amount of evidence and on the relevance of the findings. Any disagreement regarding inclusion was resolved by discussion between the two investigators. 


\section{Data extraction}

The full texts of the selected papers were reviewed and the relevant data on the new imaging methods for the assessment of implant therapy outcome were extracted. In particular, these included information on the methodology and the findings of the included studies.

The extracted data were synthesised by the lead author and the synthesis was discussed with all authors. 


\section{Results}

\section{Cone beam computed tomography}

Due to its capacity to provide cross-sectional images of the bone at lower radiation dose in comparison with multislice computed tomography (MCT), cone beam computed tomography (CBCT) is currently the most widely used technique for three-dimensional (3D) imaging of bone. It has to be emphasized that the radiation burden of CBCT is considerably higher as compared to the intraoral radiography (Harris et al. 2012). Therefore, preoperative CBCT imaging in implant dentistry should be limited to the situations in which more information is needed following adequate clinical examination and conventional 2D radiography (Harris et al. 2012).

Postoperative imaging of dental implants by means of CBCT cannot be justified in the absence of a direct benefit for the patient except as part of ethically approved clinical research. Cross-sectional imaging may be helpful for the diagnosis and management of certain complications, such as nerve damage or postoperative infections (Harris et al. 2012). In the context of this review the focus is on the value of CT assessing the situation after implant placement.

In ethically approved clinical research, computed tomography (CT) can be used to evaluate:

- the bone and the soft tissue

- the implant position with reference to the anatomical structures and the pre-operatively planned implant position.

Assessment of bone and soft tissue

$\mathrm{CT}$ is increasingly being used for $3 \mathrm{D}$ assessment of bone following ridge preservation (Jung et al. 2013b, Pang et al. 2014), sinus floor elevation (Altintas et al. 2013, Arasawa et al. 2012, Calasans-Maia et al. 2014, Cosso et al. 2014, He et al. 2013, Sbordone et al. 2013, Tsai et al. 2014), ridge augmentation (Dasmah et al. 2012, de Freitas et al. 2013), and implant placement with or without simultanous bone augmentation (Amorfini et al. 2014, Assaf et al. 2013, Benic et al. 2012a, Buser et al. 2013a, Buser et al. 2013b, Cortes et al. 2013, Degidi et al. 2012, Fu et al. 2014, Jung et al. 2015, Kehl et al. 2011, Koutouzis et al. 2014, Lemes et al. 2014, 
Miyamoto \& Obama 2011, Mounir et al. 2014, Roe et al. 2012, Rossi et al. 2013, Schropp et al. 2014, Vera et al. 2012, Verdugo et al. 2011).

In addition, CBCT was used to visualize the external contour of the periimplant soft tissue (Benic et al. 2012a, Jung et al. 2015, Kaminaka et al. 2014, Kehl et al. 2011). This can be accomplished by applying radio-opaque contrast materials (e.g. tin foils or flowable composite resins) on the mucosal surface (Benic et al. 2012a, Kehl et al. 2011). Another possibility for the visualization of the mucosa within the CBCT is to displace the lips and the cheeks from the alveolar process by means of lip retractors or cotton rolls (Januario et al. 2011, Kaminaka et al. 2014). Moreover, CT images can be matched with 3D surface scans to allow the visualization of the mucosal surface with reference to the bone and the implant.

Similarly to MCT (Kalender et al. 1987, Zhao et al. 2000), CBCT is susceptible to the appearance of artefacts generated by highly X-ray-absorbing objects, such as dental reconstructions (Draenert et al. 2007, Schulze et al. 2011). In CBCT images, artefacts expressed by altered grey values are always present in the proximity of titanium implants (Benic et al. 2013, Schulze et al. 2010). It is, therefore, controversial whether CBCT represents an adequate technique for the assessment of structures in the close proximity of dental implants.

In one in-vitro study a pattern was detected related to the distribution of artefacts around titanium implants in CBCT (Benic et al. 2013). Compared to control sites without implants, increased grey values were present at the buccal and lingual aspects of all the implant sites, whereas the regions with reduced grey values were located along the long axis of the mandibular body. Another study compared different implant materials with regards to the appearance of artefacts in CBCT (SanchoPuchades et al. 2014). It was found that zirconium dioxide implants generate significantly more artefacts in comparison to titanium and titanium-zirconium implants. The intensity of artefacts around zirconium dioxide implants was on average three times as high as around titanium implants.

In a recent trial, artefacts around titanium and lead rods were analysed in 13 different CBCT devices and one MCT device, including high-dose and low-dose exposure protocols (Pauwels et al. 2013). The artefacts were always present and, in general, no significant improvement was observed for high-dose scan protocols. It 
was concluded that, currently, the possibility for artefact reduction based on the adjustment of exposure parameters in CBCT is clinically not feasible.

Algorithms within 3D imaging software were developed to reduce metal generated artefacts. One in vitro study found that an artefact reduction algorithm does not significantly correct the altered grey values in the vicinity of implants (Parsa et al. 2014). Another study investigated the accuracy of CBCT images obtained with and without the use of artefact reduction modes in detecting simulated peri-implant defects (Kamburoglu et al. 2013). No difference was found between CBCT images obtained with and without artefact reduction algorithms.

A recent study found that the adjustment of image settings in CBCT imaging software has an influence on the detectability of peri-implant bone defects (deAzevedo-Vaz et al. 2013). In particular, different combinations of image pre-settings ("filters") allowed optimizing the visibility of peri-implant bone dehiscences. As far as CBCT image settings are concerned, it has to be pointed out that, currently, there are no guidelines for standardized CBCT image setting (e.g. window level and width) for evaluating of bone at dental implants. When examining the tissue contours in CBCT images, it is recommended not to limit the assessment to one 2D cross-section, but rather to analyse the volume in the entire region-of-interest. Moreover, the window level and width need to be adjusted to allow the identification of both the implant structures (e.g. threads and internal structure) as well as bone contour.

Dual-energy computed tomography (DECT) was recently developed to overcome certain limitations of single-energy CT systems including the difficulty to differentiate tissues (Johnson et al. 2007). In DECT, two CT data ssets are acquired with different $x$-ray spectra that are generated using two different tube potentials. A recent study showed that DECT in combination with a particular data reconstruction process has the potential to reduce the intensity of artefacts around implants and enhance the visualization of the peri-implant tissue (Tanaka et al. 2013).

One focus of the recent research analysing the value of CBCTs for the clinic is the capacity to assess bone and bone defects around implants.

With regards to the capacity to assess peri-implant bone defects, several studies concluded that the measurements from CBCT scans rendered sub-millimetric deviations in the dimension of the true peri-implant defects (Fienitz et al. 2012, Golubovic et al. 2012, Kamburoglu et al. 2014, Ritter et al. 2014). An in vitro trial 
found that periapical radiographs were better than $\mathrm{CBCT}$ in diagnosing peri-implant bone defects, when the defect width was below $0.35 \mathrm{~mm}$. (Dave et al. 2013). Another study concluded that the evaluation of peri-implant bone defects by means of CBCT is not accurate for sites with a defect width $<0.5 \mathrm{~mm}$ (Fienitz et al. 2012). Moreover, it was found that $\mathrm{CBCT}$ is not adequate for the distinction between bone and bone substitute materials.

As far as the measurement of bone dimensions around implants is concerned, one trial concluded that CBCT is precise in determining the apico-coronal level of marginal bone (Shiratori et al. 2012). Other studies investigated the minimal thickness of peri-implant bone that can be identified using CBCT (Naitoh et al. 2012, Razavi et al. 2010). It was concluded that CBCT provides accurate measurements at sites with a bone thickness $>0.5 \mathrm{~mm}$. In contrast, when bone thickness measured < $0.5 \mathrm{~mm}$, the bone plate was either underestimated or not detectable. The threshold of bone thickness for the detection by СВCT was dependent on the image resolution. Scans with higher resolution and thus smaller voxels allowed identifying thinner periimplant bone plates (Naitoh et al. 2012, Razavi et al. 2010).

Based on the results of these trials, it can be concluded that CBCT has the potential to allow the assessment of peri-implant bone plates and of peri-implant defects with a thickness $>0.5 \mathrm{~mm}$. Due to the considerably higher artefact intensity generated by zirconia, it remains to be determined whether CBCT can provide accurate imaging of zirconia implants.

With regards to the analysis, in the majority of the clinical studies quantitative linear measurements of peri-implant tissues were performed with reference to the implant in the transaxial bucco-oral cross-section. The parameters usually assessed included bone and soft tissue thicknesses as well as the coronal level of the ridge crest and of the mucosal margin at the mid-buccal aspect of the test implant. In contrast, some studies measured the volume of the augmented regions (Amorfini et al. 2014, Arasawa et al. 2012, Pang et al. 2014).

When performing CT scans at different time points, the presence and the identification of an adequate reference structure is required to allow standardized measurements. An additional improvement for assessing tissue changes over time is to superimpose different $3 \mathrm{D}$ data sets thus allowing measuring in the identical region (Amorfini et al. 2014, Arasawa et al. 2012, Jung et al. 2013b). 
When it comes to the assessment of bone density, crucial differences exist between MCT and CBCT. The measurements of bone density in CBCT are not easily comparable, because the grey values in CBCT are influenced by different factors, such as the CBCT device, the exposure parameters, and the position of the regionof-interest within the field-of-view (Nackaerts et al. 2011). Although attempts have been made to correct for grey value variability, no reliable system has been developed so far. Hence, the quantitative use of grey values cannot generally be recommended at this point in time (Pauwels et al. 2015).

\section{Assessment of implant position}

Postoperative cross-sectional radiographic imaging may be indicated for the diagnosis and management of certain complications. Essentially, they were defined as undesired implant intrusion into anatomic structures, such as mandibular canal, maxillary sinus and incisive canal (Harris et al. 2012).

In the majority of studies assessing the deviation between the preoperatively virtual 3D planning and the real position of the implant, the post-operative CT image was superimposed with the virtually planned implants (Tahmaseb et al. 2014). The combination of optical scan of implants with pre-operative CBCT can be applied for the radiation-free evaluation of the $3 \mathrm{D}$ implant position and the spatial relation to the neighbouring anatomical structures (Stoetzer et al. 2014, von See et al. 2014).

\section{Magnetic resonance imaging}

The assessment of anatomical structures and pathological processes in the maxillofacial region by means of magnetic resonance imaging (MRI) has been performed for over 30 years (Baba et al. 1999, Eley et al. 2012, Modder et al. 1985) (Assaf et al. 2014). MRI allows the cross-sectional display of soft and hard tissues without using ionizing radiation (Gahleitner et al. 1999). When used for implant planning, it was shown that MRI provides similar amount of information in comparison to the CT-based analysis (Aguiar et al. 2008, Eggers et al. 2005a, Gray et al. 2003, Imamura et al. 2004, Pompa et al. 2010).

MRI was clinically used for the assessment of treatment outcome after sinus lifting procedure (Gray et al. 2001, Senel et al. 2006). In a previous study, 13 edentulous maxillary regions were evaluated before and three months after the sinus 
floor elevation (Senel et al. 2006). The increase in the vertical amount of hard tissue was assessed on MRI. The investigators reported high quality of images and no artefacts. It was, therefore, stated that MRI allows an accurate assessment of the outcome of sinus floor elevation.

The appearance of artefacts in MRI depends on the composition and the physical properties of the object under investigation. It was reported that ferromagnetic elements induce inhomogeneity in the magnetic field and, thereby, cause artefacts in MRI (Klinke et al. 2012, Starcukova et al. 2008, Tymofiyeva et al. 2013).

In an in vitro trial, the extent of artefacts in MRI was investigated around metallic restorations and titanium implants (Eggers et al. 2005b). The presence and the intensity of artefacts were evaluated by matching the MRI images of the same specimen with and without the reconstructive materials. The image analysis revealed no artefacts around amalgam and gold reconstructions. In contrast, artefacts appeared in the proximity of titanium implants. This finding was explained by the presence of traces of ferromagnetic iron in the titanium alloy.

A recent study examined imaging of titanium and zirconia implants by means of MRI (Duttenhoefer et al. 2014). Zirconia implants induced minimal artifacts and were accurately displayed in MRI. In contrast, extensive artefacts appeared around titanium implants. In addition, the vertical amount of bone apical to the implant apex was assessed with MRI and micro CT. For titanium implants, the MRI-based assessment significantly underestimated the amount of bone in comparison to the micro CT control measurement. For the assessment at zirconia implants, no differences were found between MRI and micro CT. It was, therefore, concluded that MRI represent an accurate modality for 3D imaging of zirconia implants and the surrounding tissues.

\section{Ultrasonography}

Ultrasonography is a non-invasive diagnostic tool commonly used in medical imaging that is particularly indicated for the examination of the soft tissue anatomy and certain pathologies, such as hematoma or abscess. Ultrasonography allows the display of oral mucosa and underlying tooth, implant and bone surfaces (Choi et al. 2012, Culjat et al. 2008, Salmon \& Le Denmat 2012). 
Ultrasonic devices have been used in several investigations for the measurement of the thickness of the oral mucosa (Eghbali et al. 2014, Muller et al. 1999, Salmon \& Le Denmat 2012).

A recent study evaluated the validity and the reproducibility of the ultrasonographic assessment of the mucosal thickness (Eghbali et al. 2014). Human cadaver edentulous maxillae were used to determine mucosal thickness at 100 different sites. Soft tissue thickness as recorded with the ultrasonic device was compared with the values measured by using micro CT. The ultrasonographic assessment rendered an underestimation of the values of approximately $0.1 \mathrm{~mm}$ in comparison with the micro CT analysis. This finding is in agreement with data from previous trials investigating the use of ultrasonic devices for the measurement of the mucosal thickness (Culjat et al. 2008, Culjat et al. 2012, Muller et al. 1999). It can, therefore, be concluded that ultrasonography represents a reliable and reproducible method to evaluate the thickness of the oral soft tissue.

In the previously mentioned publication, ultrasonography was clinically used for repeated measurements of the thickness of peri-implant mucosa at single implants (Eghbali et al. 2014). It was found that grafting with connective tissue substantially thickened the peri-implant mucosa. Moreover, the grafted soft tissue exhibited high dimensional stability over a 9-month period.

A recent in vitro trial assessed the use of ultrasonography for the imaging of implants with and without peri-implant bone defects (Choi et al. 2012). In this study, bone and implant surfaces were clearly displayed below the soft tissue. Moreover, the ultrasonographic device allowed the identification of the peri-implant bone dehiscences. Ultrasonographic measurements of peri-implant bone defects were evaluated in a previous clinical study with 25 patients (Bertram \& Emshoff 2008). The vertical dimension of bone defects was sonographically assessed at the buccal aspect of 29 implants. These values were compared with the intra-operative measurements obtained after flap elevation by using a periodontal probe. The defects with $<6 \mathrm{~mm}$ of depth were accurately assessed by means of ultrasonography. In contrast, the sonographic assessment of the bone defects with > $6 \mathrm{~mm}$ of depth rendered poor reliability. 


\section{Optical scanning}

Optical scanners were developed for digital impressions of teeth, implants and surrounding soft tissues. These devices provide 3D digital data sets that can also be used to evaluate:

- the soft tissue contour,

- the implant position with reference to the anatomical boundaries and the pre-operatively planned implant position,

- the prosthetic misfit of implant-supported fixed dental prosthesis.

\section{Assessment of soft tissue contour}

The most frequently used parameters for the assessment of peri-implant mucosal esthetics are vertical levels of the buccal mucosal margin and of the interproximal papillae (Benic et al. 2012b). However, the knowledge remains limited on the overall 3D behaviour of peri-implant soft tissues and its influence on the esthetic outcome of implant therapy.

Laboratory and intraoral optical scanners in combination with image analysis software are being increasingly used for 3D assessment of the change of mucosal contours resulting from implant placement and augmentation procedures (Abrahamsson 2011, Capelli et al. 2013, Friberg \& Jemt 2012, Gallucci et al. 2007, Jemt \& Lekholm 2003, 2005, Schneider et al. 2011, Schneider et al. 2014). The optical scanning allows the longitudinal quantitative evaluation of volumetric changes by superimposing 3D images generated at different time points. Generally, the baseline data set is used as reference for the matching of the subsequent $3 \mathrm{D}$ images. To allow precise matching of multiple 3D images, adequate reference structures need to be selected and identified in each data set. These reference structures need to remain stable during the observation period. Normally, surfaces of teeth and fixed reconstructions are used as reference structures. To date, many 3D image analysis softwares are available. They allow superimposition of images using the predefined reference structures by applying best-fit algorithms. It has to be taken into consideration that, at the moment, the accuracy of digital 3D matching procedures is not sufficiently investigated. 
The intraoral situation can either be recorded indirectly by means of a conventional impression procedure and the fabrication of a study model that is subsequently scanned with an optical scanner, or by direct intraoral scanning. Direct intaoral scanning allows reducing the number of working steps and, thereby, increasing efficiency. In addition, by eliminating intermediate steps the direct method has the potential to increase the accuracy of the capturing procedure.

When it comes to the analysis, in the majority of the clinical investigations this technology was applied for measurements of the changes of ridge contour in the bucco-oral direction. In many studies, the measurement was performed in one crosssectional image displaying the tissue contours at different time points. The analysis was done either by linear measurement between two points (Gallucci et al. 2007) or by assessing the area between 2D tissue contours at two time points (Jemt \& Lekholm 2003, 2005). Another possibility is to measure the volume between 3D contours within a defined area-of-interest (Friberg \& Jemt 2012, Schneider et al. 2011, Schneider et al. 2014). The results are provided as increase or reduction of volume in relation to the baseline time point. In order to compare the volume alterations between sites with different areas-of-interest, the volume changes are averaged over the measured area. The resulting relative value represents the mean linear change between two contours in the direction perpendicular to the area-ofinterest (Schneider et al. 2011, Schneider et al. 2014).

The 3D optical scanning method is generally not adequate for the assessment of the interdental papillae, due to the incomplete impression of the surfaces in the interproximal regions. In the majority of clinical investigations, the assessment of the papillary changes was performed by direct intraoral linear measurements. In a previous study, the width and the height of the maxillary process in the interproximal region was measured with optical scanning of study casts, after the removal of the implant-supported reconstructions (Gallucci et al. 2007).

\section{Assessment of implant position}

The combination of optical scan of implants with pre-operative CBCT image can be applied for the radiation-free evaluation of the 3D implant position and the spatial relation to the neighbouring anatomical structures (von See et al. 2014). The superimposition of CBCT and optical scans can be performed with commercially 
available software by selecting adequate landmarks, which can be identified using in both 3D images. This procedure permits identifying the implant position following placement and allows identifying possible damage to adjacent structures. Damage caused by the preparation of the implant bed can, however, not be visualized using this method.

Furthermore, this procedure can be used to determine variations between the preoperative virtual 3D planning and the actual position of the implant following placement (Stoetzer et al. 2014).

\section{Assessment of prosthesis misfit}

Optimizing the fit of the reconstructions to the implants is a common goal in prosthodontics aimed at improving clinical procedures and reducing the rate of biological and technical complications. The methods usually used in the clinic to assess the misfit between the framework of the reconstructions and the supporting implants encompass clinical examination and 2D intraoral radiography. In addition, indirect techniques using strain gauges (Karl et al. 2004, Smedberg et al. 1996), photogrammetry (Jemt \& Book 1996, Jemt et al. 1996), mechanical and optical scanners in combination with computer software (Al-Fadda et al. 2007, Hjalmarsson et al. 2010, Jemt \& Hjalmarsson 2012, Papaspyridakos et al. 2012) have been used to assess the misfit between the reconstructions and the implants.

In the past years, technical improvements and market penetration of new CAD/CAM systems for fabrication of reconstructions have also lead to increased use of intraoral optical impressions. Recent studies found digital scans to be as accurate as conventional impression techniques (Ender \& Mehl 2011, van der Meer et al. 2012). However, intraoral scanners still face some limitations regarding their widespread clinical use. They render inadequate results when scanning patient situations with large edentulous gaps between the implants (Andriessen et al. 2014). The main reason for the inaccuracy of the scans seems to be the lack of anatomic landmarks for precise stitching of the multiple scans obtained by the intraoral camera. In order to overcome this problem a new method has recently been described (Jokstad \& Shokati 2014). Acrylic stents were fabricated and placed onto the patients' edentulous jaw to facilitate the stitching of the multiple images generated by the intraoral scanner. 
A recent retrospective clinical study assessed the misfit between fixed dental prosthesis (FDP) and the supporting implant abutments in patients with an edentulous jaw (Jokstad \& Shokati 2014). The implant intraoral positions were recorded by use of an intraoral scanner, and the matching surface of the detached FDP was recorded using a laboratory scanner. The misfit between the two was then calculated applying a matching-software. The patients had longitudinally been monitored and clinical parameters including bone loss and technical complication rates had been assessed for an average of 19 years. The degree of misfit positively correlated with the rate of technical complication (screw loosening and screw fracture) that had occurred during the previous 19 years, but not with the amount of bone loss (Jokstad \& Shokati 2014).

Although, a correlation between the amount of misfit and the occurrence of technical complications has been reported, it is presently unknown which maximum degree of misfit will not lead to an increase of clinical complications.

\section{Spectrophotometry}

Colour assessment of the mucosa or of the reconstruction can be performed objectively by using either a reflectance spectrophotometer (Ishikawa-Nagai et al. 2007, Jung et al. 2008, Park et al. 2007) or hyper-spectral imaging (van Brakel et al. 2011). Spectrophotometry is the method most commonly used to assess color differences in dentistry. When compared with the ability of the human eye to assess colors in a clinical setting, spectrophotometry was found to both capture smaller differences in color and to achieve higher reproducibility of the assessments (Gehrke et al. 2009, Johnston \& Kao 1989).

Spectrophotometer generates a digital image of an object, which can be displayed on a computer screen. Subsequently, the actual measurement is performed for a selected area on the computer display. The spectral analysis of the region-of-interest provides the CIE-Lab (Commission Internationale de l'Eclairage) colour coordinates: $L=$ lightness, $a=$ chroma along red-green axis, and $b=$ chroma along yellow-blue axis. The colour differences between two sites or situations are expressed as differences of the colour components $\Delta \mathrm{L}, \Delta \mathrm{a}, \Delta \mathrm{b}$, and the resulting total colour difference $\Delta \mathrm{E}$. The total colour difference between two situations or sites $(\Delta \mathrm{E})$ is calculated by using the following formula: $\Delta \mathrm{E}=\left[(\mathrm{L} 1-\mathrm{L} 2)^{2}+(\mathrm{a} 1-\mathrm{a} 2)^{2}+(\mathrm{b} 1-\mathrm{b} 2)^{2}\right]^{1 / 2}$ (CIE Pub 2004). 
Under standardized laboratory conditions, the human eye is able to distinguish a colour difference $\Delta \mathrm{E}$ of 1 (Kuehni \& Marcus 1979)\& Marcus 1979). For the intraoral evaluation of dental hard tissue, $\Delta \mathrm{E}$ values ranging from 2 to 4 were reported as the limit of perceptibility for color differences (Douglas \& Brewer 1998, Douglas et al. 2007, Johnston \& Kao 1989, Yilmaz et al. 2009).

In implant dentistry the spectrophotometer has mainly been used for the evaluation of the peri-implant mucosa. Studies in this field aimed at investigating the treatment possibilities for improving the colour match of the peri-implant mucosa to the natural gingiva. For the evaluation of clinically relevant colour differences, the $\Delta \mathrm{E}$ value of 3.7 was commonly considered as the threshold value for intraoral colour distinction by the human eye (Johnston \& Kao 1989). This threshold value had, however, been determined for the evaluation of dental hard tissues. A recent in-vitro trial aimed at determining the threshold value for the detection of colour differences of human gingiva by the human eye (Sailer et al. 2014). The lightness of digital images of human gingiva was gradually modified by using a software. Pairs of digitally modified and original images were randomly presented on a computer screen. Dentists, dental technicians and lay people assessed visible differences between images. The overall threshold value $\Delta \mathrm{E}$ amounted to 3.1.

When assessing the clinically visible colour differences, it has to be taken into account that normal colour differences between the natural gingiva of contralateral teeth were reported to measure $\Delta \mathrm{E}$ of 2.7 (Ishikawa et al. 1988). In a recent clinical study dental professionals were asked to assess the quality of the color match between peri-implant mucosa and natural gingiva sites on a scale ranging from perfect match to clinically unacceptable (Paniz et al. 2014). Subsequently, the $\Delta E$ values between these peri-implant mucosa and natural gingiva sites were assessed using a spectrophotometer. The subjective perfect matching presented values of $\Delta \mathrm{E}$ $=6.6$, the subjective good matching corresponded to average values $\Delta \mathrm{E}$ of 8.5 , and the distinguishable evaluations corresponded to $\Delta \mathrm{E}$ values of 15.5 .

The insertion of implant-supported reconstructions induces a discoloration of the peri-implant mucosa (Ishikawa-Nagai et al. 2007, Jung et al. 2008). Previous invitro and in-vivo studies evaluated the influence of the colour of the reconstructive material and of the soft tissue thickness on the colour of the peri-implant mucosa (Bressan et al. 2011, Buchi et al. 2014, Jung et al. 2008, Jung et al. 2007, Pecnik et 
al. 2014, Sailer et al. 2009) (Happe et al. 2013a, Happe et al. 2013b). Various trials found that mucosal thickness significantly affected the degree of soft tissue discoloration caused by the colour of reconstructive material (Happe et al. 2013b, Jung et al. 2007, Pecnik et al. 2014). It was concluded that when mucosal thickness exceeded $2 \mathrm{~mm}$, the discoloration of mucosa caused by the underlying materials was below the $\Delta \mathrm{E}$ threshold value of 3.7 (Jung et al. 2007, Pecnik et al. 2014). Therefore, the mucosal discoloration caused by the underlying restorative material can clinically be addresses using two different approaches: improving the optical properties of the restorative material and thickening of the covering mucosa.

Another factor not commonly assessed in previous clinical studies is the health of the tissue under evaluation. It has been proposed that light in the visible near-infrared spectral region can be used to detect the degree of tissue inflammation (Sowa et al. 2006, Sowa et al. 2001). A clinical study examining healthy implants and those with mucositis and peri-implantitis found that optical spectroscopy correlates with various components of the inflammatory process in the peri-implant mucosa, specifically, tissue perfusion, oxygenation and hydration (Nogueira-Filho et al. 2011). Moreover, it was reported that haemoglobin peaks are visible in the reflection spectrum of hyper-spectral imaging (van Brakel et al. 2011). These technologies may, therefore, be considered a possible approach for the monitoring of soft tissue health and diagnosis of peri-implant diseases in the future.

In the majority of the clinical studies, the final colour of the covering periimplant mucosa was compared with the gingiva at the adjacent or contralateral tooth. Ideally, three mesurements should be made, when assessing color changes in a clinical setting: i) the colour match between the test and the control sites prior to the intervention, ii) the colour match between the test and the control sites after the intervention, and iii) the colour change at the test site from prior to after the intervention.

\section{Optical coherence tomography}

Optical coherence tomography (OCT) is an imaging modality that allows the cross-sectional display of tissues and biomaterials (Clarkson 2014, Colston et al. 1998, Otis et al. 2000). OCT is based on the concept of low-coherence interferometry, in which broadband light is projected over a sample under investigation (Huang et al. 1991). The light rays penetrate the object and the 
backscattered photons provide depth-related information abouth the object. This information is transformed into a 2D image by computer software.

A recent in vitro study investigated the potential of OCT for the detection of marginal gaps at the implant-abutment interface (Kikuchi et al. 2014). Gaps sized 50 $\mu \mathrm{m}, 100 \mu \mathrm{m}, 150 \mu \mathrm{m}$, and $200 \mu \mathrm{m}$ were created between implants with external hexagonal connection and titanium abutments. Subsequently, porcine mucosa samples with $0.5 \mathrm{~mm}, 1 \mathrm{~mm}, 1.5 \mathrm{~mm}$, or $2 \mathrm{~mm}$ of thickness were placed onto the implant-abutment interfaces. It was found that when covered with mucosa of a thickness of $0.5 \mathrm{~mm}$ and $1 \mathrm{~mm}$, the gaps measuring $\geq 100 \mu \mathrm{m}$ could be detected and accurately measured. When the mucasal thickness reached $1.5 \mathrm{~mm}$, however, only approximately $70 \%$ of the gaps sized $150 \mu \mathrm{m}$ and $200 \mu \mathrm{m}$ could be detected. Finally, in cases with a mucosal thickness of $2 \mathrm{~mm}$ the majority of the gaps could not be detected. 


\section{Conclusions}

Based on the findings of the present narrative review it can be concluded that:

- Various new digital imaging techniques were recently introduced for the assessment of outcomes in oral rehabilitation with dental implants. The majority of them have, however, not yet been sufficiently validated in clinical studies.

- In clinical research, cone beam compute tomography (CBCT) is increasingly being used for 3D assessment of bone and soft tissue following augmentation procedures and implant placement. Currently, there are no effective methods for the reduction of artifacts around dental implants in CBCT. Despite this limitation, CBCT has the potential to allow the assessment of bone plates and bone defects around titanium implants. Due to the considerably higher artifact intensity generated by zirconia, it remains to be determined whether CBCT can provide accurate imaging of zirconia implants.

- The assessment of anatomic structures and pathological processes in the maxillofacial region by means of magnetic resonance imaging (MRI) has been performed for over 30 years. MRI potentially represents an accurate modality for 3D imaging of zirconia implants and the surrounding tissues. In contrast, MRI-based imaging of titanium implants appears to be susceptible to the appearance of artifacts.

- Ultrasonography has the potential to allow an accurate and reproducible assessment of the peri-implant mucosa. In addition, ultrasonography may be considered a possible approach non-ionizing radiation method for the assessment of bone defects and soft tissue pathology originated from surgical complications.

- Optical scanning is increasingly being used for the 3D assessment of the changes in the soft tissue contour. The combination of optical scan with pre-operative $\mathrm{CBCT}$ can be applied for the determination of the $3 \mathrm{D}$ implant 
position and the spatial relation to the neighbouring anatomical structures. Furthermore, optical scanners may represent an efficient clinical method for an accurate quantitative assessment of the misfit between the reconstructions and the implants.

- Spectrophotometry is the method most commonly used to objectively assess color differences in dentistry. In implant dentistry spectrophotometric assessments aimed at investigating the optical properties of the restorative material and of the covering mucosa for assessing the color match of the peri-implant mucosa to the natural gingiva. New optical imaging techniques, such as spectroscopy and hyperspectral imaging, may be considered possible approaches for monitoring peri-implant soft tissue health and disease.

- Optical coherence tomography (OCT) appears a promising imaging modality for the detection of the marginal gaps at the implant-abutment interface. However, its diagnostic capacity seems to be limited to sites with thin mucosa. 


\section{Conflict of interest and sources of funding statement}

The authors declare no conflict of interest regarding any part of the systematic review.

The present systematic review was funded by the Clinic of Fixed and Removable Prosthodontics and Dental Material Science, University of Zurich, Switzerland. 


\section{Acknowledgements}

The authors gratefully acknowledge Gisela Müller (Clinic of Fixed and Removable Prosthodontics and Dental Material Science, Center of Dental Medicine, University of Zurich, Switzerland) for assistance in preparing the manuscript. 


\section{References}

Abrahamsson, P. (2011) Intra-oral soft tissue expansion and volume stability of onlay bone grafts. Swedish Dental Journal. Supplement: 11-66.

Aguiar, M. F., Marques, A. P., Carvalho, A. C. \& Cavalcanti, M. G. (2008) Accuracy of magnetic resonance imaging compared with computed tomography for implant planning. Clinical Oral Implants Research 19: 362-365.

Al-Fadda, S. A., Zarb, G. A. \& Finer, Y. (2007) A comparison of the accuracy of fit of 2 methods for fabricating implant-prosthodontic frameworks. International Journal of Prosthodontics 20: 125-131.

Altintas, N. Y., Senel, F. C., Kayipmaz, S., Taskesen, F. \& Pampu, A. A. (2013) Comparative radiologic analyses of newly formed bone after maxillary sinus augmentation with and without bone grafting. Journal of Oral and Maxillofacial Surgery 71: 1520-1530.

Amorfini, L., Migliorati, M., Signori, A., Silvestrini-Biavati, A. \& Benedicenti, S. (2014) Block allograft technique versus standard guided bone regeneration: A randomized clinical trial. Clinical Implant Dentistry and Related Research 16: 655-667.

Andriessen, F. S., Rijkens, D. R., van der Meer, W. J. \& Wismeijer, D. W. (2014) Applicability and accuracy of an intraoral scanner for scanning multiple implants in edentulous mandibles: A pilot study. Journal of Prosthetic Dentistry 111: 186-194.

Arasawa, M., Oda, Y., Kobayashi, T., Uoshima, K., Nishiyama, H., Hoshina, H. \& Saito, C. (2012) Evaluation of bone volume changes after sinus floor augmentation with autogenous bone grafts. International Journal of Oral and Maxillofacial Surgery 41: 853-857.

Assaf, A. T., Zrnc, T. A., Remus, C. C., Schonfeld, M., Habermann, C. R., Riecke, B., Friedrich, R. E., Fiehler, J., Heiland, M. \& Sedlacik, J. (2014) Evaluation of four different optimized magnetic-resonance-imaging sequences for visualization of dental and maxillo-mandibular structures at 3 t. Journal of Cranio-Maxillo-Facial Surgery 42 : 1356-1363.

Assaf, J. H., Zanatta, F. B., de Brito, R. B., Jr. \& Franca, F. M. (2013) Computed tomographic evaluation of alterations of the buccolingual width of the alveolar ridge after immediate implant placement associated with the use of a synthetic bone substitute. International Journal of Oral and Maxillofacial Implants 28: 757-763.

Baba, Y., Yamashita, Y., Onomichi, M., Murakami, R. \& Takahashi, M. (1999) Dynamic magnetic resonance imaging of head and neck lesions. Topics in Magnetic Resonance Imaging 10: 125-129.

Benic, G. I., Jung, R. E., Siegenthaler, D. W. \& Hammerle, C. H. (2009) Clinical and radiographic comparison of implants in regenerated or native bone: 5-year results. Clinical Oral Implants Research 20: 507-513. 
Benic, G. I., Mokti, M., Chen, C. J., Weber, H. P., Hammerle, C. H. \& Gallucci, G. O. (2012a) Dimensions of buccal bone and mucosa at immediately placed implants after 7 years: A clinical and cone beam computed tomography study. Clinical Oral Implants Research 23: 560-566.

Benic, G. I., Sancho-Puchades, M., Jung, R. E., Deyhle, H. \& Hammerle, C. H. (2013) In vitro assessment of artifacts induced by titanium dental implants in cone beam computed tomography. Clinical Oral Implants Research 24: 378-383.

Benic, G. I., Wolleb, K., Sancho-Puchades, M. \& Hammerle, C. H. (2012b) Systematic review of parameters and methods for the professional assessment of aesthetics in dental implant research. Journal of Clinical Periodontology 39 Suppl 12: 160-192.

Bertram, S. \& Emshoff, R. (2008) Sonography of periimplant buccal bone defects in periodontitis patients: A pilot study. Oral Surgery, Oral Medicine, Oral Pathology, Oral Radiology and Endodontics 105: 99-103.

Bressan, E., Paniz, G., Lops, D., Corazza, B., Romeo, E. \& Favero, G. (2011) Influence of abutment material on the gingival color of implant-supported all-ceramic restorations: A prospective multicenter study. Clinical Oral Implants Research 22: 631-637.

Buchi, D. L., Sailer, I., Fehmer, V., Hammerle, C. H. \& Thoma, D. S. (2014) Allceramic single-tooth implant reconstructions using modified zirconia abutments: A prospective randomized controlled clinical trial of the effect of pink veneering ceramic on the esthetic outcomes. International Journal of Periodontics and Restorative Dentistry 34: 29-37.

Buser, D., Chappuis, V., Bornstein, M. M., Wittneben, J. G., Frei, M. \& Belser, U. C. (2013a) Long-term stability of contour augmentation with early implant placement following single tooth extraction in the esthetic zone: A prospective, cross-sectional study in 41 patients with a 5- to 9-year follow-up. Journal of Periodontology 84: 15171527.

Buser, D., Chappuis, V., Kuchler, U., Bornstein, M. M., Wittneben, J. G., Buser, R., Cavusoglu, Y. \& Belser, U. C. (2013b) Long-term stability of early implant placement with contour augmentation. Journal of Dental Research 92: 176S-182S.

Cairo, F., Sanz, I., Matesanz, P., Nieri, M. \& Pagliaro, U. (2012) Quality of reporting of randomized clinical trials in implant dentistry. A systematic review on critical aspects in design, outcome assessment and clinical relevance. Journal of Clinical Periodontology 39 Suppl 12: 81-107.

Calasans-Maia, M. D., Mourao, C. F., Alves, A. T., Sartoretto, S. C., de Uzeda, M. J. \& Granjeiro, J. M. (2014) Maxillary sinus augmentation with a new xenograft: A randomized controlled clinical trial. Clinical Implant Dentistry and Related Research.

Capelli, M., Testori, T., Galli, F., Zuffetti, F., Motroni, A., Weinstein, R. \& Del Fabbro, M. (2013) Implant-buccal plate distance as diagnostic parameter: A prospective 
cohort study on implant placement in fresh extraction sockets. Journal of Periodontology 84: 1768-1774.

Choi, M., Culjat, M. O., Singh, R. S. \& White, S. N. (2012) Ultrasound imagery for dental implant diagnosis and treatment planning in a porcine model. Journal of Prosthetic Dentistry 108: 344-353.

Clarkson, D. M. (2014) An update on optical coherence tomography in dentistry. Dental Update 41: 174-176, 179-180.

Colston, B. W., Jr., Everett, M. J., Da Silva, L. B., Otis, L. L., Stroeve, P. \& Nathel, H. (1998) Imaging of hard- and soft-tissue structure in the oral cavity by optical coherence tomography. Appl Opt 37: 3582-3585.

Cortes, A. R., Cortes, D. N. \& Arita, E. S. (2013) Correction of buccal dehiscence at the time of implant placement without barrier membranes: A retrospective cone beam computed tomographic study. International Journal of Oral and Maxillofacial Implants 28: 1564-1569.

Cosso, M. G., de Brito, R. B., Jr., Piattelli, A., Shibli, J. A. \& Zenobio, E. G. (2014) Volumetric dimensional changes of autogenous bone and the mixture of hydroxyapatite and autogenous bone graft in humans maxillary sinus augmentation. A multislice tomographic study. Clinical Oral Implants Research 25: 1251-1256.

Culjat, M. O., Choi, M., Singh, R. S., Grundfest, W. S., Brown, E. R. \& White, S. N. (2008) Ultrasound detection of submerged dental implants through soft tissue in a porcine model. Journal of Prosthetic Dentistry 99: 218-224.

Culjat, M. O., Choi, M., Singh, R. S. \& White, S. N. (2012) Ultrasound imaging of dental implants. Conf Proc IEEE Eng Med Biol Soc 2012: 456-459.

Dasmah, A., Thor, A., Ekestubbe, A., Sennerby, L. \& Rasmusson, L. (2012) Particulate vs. Block bone grafts: Three-dimensional changes in graft volume after reconstruction of the atrophic maxilla, a 2-year radiographic follow-up. Journal of Cranio-Maxillo-Facial Surgery 40: 654-659.

Dave, M., Davies, J., Wilson, R. \& Palmer, R. (2013) A comparison of cone beam computed tomography and conventional periapical radiography at detecting periimplant bone defects. Clinical Oral Implants Research 24: 671-678.

de Freitas, R. M., Susin, C., Spin-Neto, R., Marcantonio, C., Wikesjo, U. M., Pereira, L. A. \& Marcantonio, E., Jr. (2013) Horizontal ridge augmentation of the atrophic anterior maxilla using rhbmp-2/acs or autogenous bone grafts: A proof-of-concept randomized clinical trial. Journal of Clinical Periodontology 40: 968-975.

de-Azevedo-Vaz, S. L., Alencar, P. N., Rovaris, K., Campos, P. S. \& Haiter-Neto, F. (2013) Enhancement cone beam computed tomography filters improve in vitro periimplant dehiscence detection. Oral Surg Oral Med Oral Pathol Oral Radiol 116: 633-639. 
Degidi, M., Nardi, D., Daprile, G. \& Piattelli, A. (2012) Buccal bone plate in the immediately placed and restored maxillary single implant: A 7-year retrospective study using computed tomography. Implant Dentistry 21: 62-66.

Douglas, R. D. \& Brewer, J. D. (1998) Acceptability of shade differences in metal ceramic crowns. Journal of Prosthetic Dentistry 79: 254-260.

Douglas, R. D., Steinhauer, T. J. \& Wee, A. G. (2007) Intraoral determination of the tolerance of dentists for perceptibility and acceptability of shade mismatch. Journal of Prosthetic Dentistry 97: 200-208.

Draenert, F. G., Coppenrath, E., Herzog, P., Muller, S. \& Mueller-Lisse, U. G. (2007) Beam hardening artefacts occur in dental implant scans with the newtom cone beam ct but not with the dental 4-row multidetector ct. Dento-Maxillo-Facial Radiology 36: 198-203.

Duttenhoefer, F., Mertens, M. E., Vizkelety, J., Gremse, F., Stadelmann, V. A. \& Sauerbier, S. (2014) Magnetic resonance imaging in zirconia-based dental implantology. Clinical Oral Implants Research.

Eggers, G., Rieker, M., Fiebach, J., Kress, B., Dickhaus, H. \& Hassfeld, S. (2005a) Geometric accuracy of magnetic resonance imaging of the mandibular nerve. DentoMaxillo-Facial Radiology 34: 285-291.

Eggers, G., Rieker, M., Kress, B., Fiebach, J., Dickhaus, H. \& Hassfeld, S. (2005b) Artefacts in magnetic resonance imaging caused by dental material. MAGMA 18: 103-111.

Eghbali, A., De Bruyn, H., Cosyn, J., Kerckaert, I. \& Van Hoof, T. (2014) Ultrasonic assessment of mucosal thickness around implants: Validity, reproducibility, and stability of connective tissue grafts at the buccal aspect. Clinical Implant Dentistry and Related Research.

Eley, K. A., Watt-Smith, S. R. \& Golding, S. J. (2012) "Black bone" mri: A potential alternative to ct when imaging the head and neck: Report of eight clinical cases and review of the oxford experience. British Journal of Radiology 85: 1457-1464.

Ender, A. \& Mehl, A. (2011) Full arch scans: Conventional versus digital impressions-an in-vitro study. Int J Comput Dent 14: 11-21.

Fienitz, T., Schwarz, F., Ritter, L., Dreiseidler, T., Becker, J. \& Rothamel, D. (2012) Accuracy of cone beam computed tomography in assessing peri-implant bone defect regeneration: A histologically controlled study in dogs. Clinical Oral Implants Research 23: 882-887.

Friberg, B. \& Jemt, T. (2012) Soft tissue augmentation in connection to dental implant treatment using a synthetic, porous material--a case series with a 6-month follow-up. Clinical Implant Dentistry and Related Research 14: 872-881.

Fu, J. H., Oh, T. J., Benavides, E., Rudek, I. \& Wang, H. L. (2014) A randomized clinical trial evaluating the efficacy of the sandwich bone augmentation technique in 
increasing buccal bone thickness during implant placement surgery: I. Clinical and radiographic parameters. Clinical Oral Implants Research 25: 458-467.

Gahleitner, A., Solar, P., Nasel, C., Homolka, P., Youssefzadeh, S., Ertl, L. \& Schick, S. (1999) [magnetic resonance tomography in dental radiology (dental mri)].

Radiologe 39: 1044-1050.

Gallucci, G. O., Mavropoulos, A., Bernard, J. P. \& Belser, U. C. (2007) Influence of immediate implant loading on peri-implant soft tissue morphology in the edentulous maxilla. International Journal of Oral and Maxillofacial Implants 22: 595-602.

Gehrke, P., Riekeberg, U., Fackler, O. \& Dhom, G. (2009) Comparison of in vivo visual, spectrophotometric and colorimetric shade determination of teeth and implantsupported crowns. Int J Comput Dent 12: 247-263.

Golubovic, V., Mihatovic, I., Becker, J. \& Schwarz, F. (2012) Accuracy of cone-beam computed tomography to assess the configuration and extent of ligature-induced peri-implantitis defects. A pilot study. Oral Maxillofac Surg 16: 349-354.

Gray, C. F., Redpath, T. W., Bainton, R. \& Smith, F. W. (2001) Magnetic resonance imaging assessment of a sinus lift operation using reoxidised cellulose (surgicel) as graft material. Clinical Oral Implants Research 12: 526-530.

Gray, C. F., Redpath, T. W., Smith, F. W. \& Staff, R. T. (2003) Advanced imaging: Magnetic resonance imaging in implant dentistry. Clinical Oral Implants Research 14: 18-27.

Happe, A., Schulte-Mattler, V., Strassert, C., Naumann, M., Stimmelmayr, M., Zoller, J. E. \& Rothamel, D. (2013a) In vitro color changes of soft tissues caused by dyed fluorescent zirconia and nondyed, nonfluorescent zirconia in thin mucosa. International Journal of Periodontics and Restorative Dentistry 33: e1-8.

Happe, A., Stimmelmayr, M., Schlee, M. \& Rothamel, D. (2013b) Surgical management of peri-implant soft tissue color mismatch caused by shine-through effects of restorative materials: One-year follow-up. International Journal of Periodontics and Restorative Dentistry 33: 81-88.

Harris, D., Horner, K., Grondahl, K., Jacobs, R., Helmrot, E., Benic, G. I., Bornstein, M. M., Dawood, A. \& Quirynen, M. (2012) E.A.O. Guidelines for the use of diagnostic imaging in implant dentistry 2011. A consensus workshop organized by the european association for osseointegration at the medical university of warsaw. Clinical Oral Implants Research 23: 1243-1253.

He, L., Chang, X. \& Liu, Y. (2013) Sinus floor elevation using osteotome technique without grafting materials: A 2-year retrospective study. Clinical Oral Implants Research 24 Suppl A100: 63-67.

Hjalmarsson, L., Ortorp, A., Smedberg, J. I. \& Jemt, T. (2010) Precision of fit to implants: A comparison of cresco and procera(r) implant bridge frameworks. Clinical Implant Dentistry and Related Research 12: 271-280. 
Huang, D., Swanson, E. A., Lin, C. P., Schuman, J. S., Stinson, W. G., Chang, W., Hee, M. R., Flotte, T., Gregory, K., Puliafito, C. A. \& et al. (1991) Optical coherence tomography. Science 254: 1178-1181.

Imamura, H., Sato, H., Matsuura, T., Ishikawa, M. \& Zeze, R. (2004) A comparative study of computed tomography and magnetic resonance imaging for the detection of mandibular canals and cross-sectional areas in diagnosis prior to dental implant treatment. Clinical Implant Dentistry and Related Research 6: 75-81.

Ishikawa, S., Nemoto, F., Furukawa, K. \& Ishibashi, K. (1988) [colorimetric studies of the gingiva. Color variation of the gingiva in the upper anterior region]. Nihon Hotetsu Shika Gakkai Zasshi 32: 821-828.

Ishikawa-Nagai, S., Da Silva, J. D., Weber, H. P. \& Park, S. E. (2007) Optical phenomenon of peri-implant soft tissue. Part ii. Preferred implant neck color to improve soft tissue esthetics. Clinical Oral Implants Research 18: 575-580.

Januario, A. L., Duarte, W. R., Barriviera, M., Mesti, J. C., Araujo, M. G. \& Lindhe, J. (2011) Dimension of the facial bone wall in the anterior maxilla: A cone-beam computed tomography study. Clinical Oral Implants Research 22: 1168-1171.

Jemt, T. \& Book, K. (1996) Prosthesis misfit and marginal bone loss in edentulous implant patients. International Journal of Oral and Maxillofacial Implants 11: 620-625.

Jemt, T. \& Hjalmarsson, L. (2012) In vitro measurements of precision of fit of implantsupported frameworks. A comparison between "virtual" and "physical" assessments of fit using two different techniques of measurements. Clinical Implant Dentistry and Related Research 14 Suppl 1: e175-182.

Jemt, T. \& Lekholm, U. (2003) Measurements of buccal tissue volumes at singleimplant restorations after local bone grafting in maxillas: A 3-year clinical prospective study case series. Clinical Implant Dentistry and Related Research 5: 63-70.

Jemt, T. \& Lekholm, U. (2005) Single implants and buccal bone grafts in the anterior maxilla: Measurements of buccal crestal contours in a 6-year prospective clinical study. Clinical Implant Dentistry and Related Research 7: 127-135.

Jemt, T., Rubenstein, J. E., Carlsson, L. \& Lang, B. R. (1996) Measuring fit at the implant prosthodontic interface. Journal of Prosthetic Dentistry 75: 314-325.

Johnson, T. R., Krauss, B., Sedlmair, M., Grasruck, M., Bruder, H., Morhard, D., Fink, C., Weckbach, S., Lenhard, M., Schmidt, B., Flohr, T., Reiser, M. F. \& Becker, C. R. (2007) Material differentiation by dual energy ct: Initial experience. European Radiology 17: 1510-1517.

Johnston, W. M. \& Kao, E. C. (1989) Assessment of appearance match by visual observation and clinical colorimetry. Journal of Dental Research 68: 819-822.

Jokstad, A. \& Shokati, B. (2014) New 3d technologies applied to assess the longterm clinical effects of misfit of the full jaw fixed prosthesis on dental implants. Clinical Oral Implants Research. 
Jung, R. E., Benic, G. I., Scherrer, D. \& Hammerle, C. H. (2015) Cone beam computed tomography evaluation of regenerated buccal bone 5 years after simultaneous implant placement and guided bone regeneration procedures - a randomized, controlled clinical trial. Clinical Oral Implants Research 26: 28-34.

Jung, R. E., Fenner, N., Hammerle, C. H. \& Zitzmann, N. U. (2013a) Long-term outcome of implants placed with guided bone regeneration ( $\mathrm{gbr}$ ) using resorbable and non-resorbable membranes after 12-14 years. Clinical Oral Implants Research 24: 1065-1073.

Jung, R. E., Holderegger, C., Sailer, I., Khraisat, A., Suter, A. \& Hammerle, C. H. (2008) The effect of all-ceramic and porcelain-fused-to-metal restorations on marginal peri-implant soft tissue color: A randomized controlled clinical trial. International Journal of Periodontics and Restorative Dentistry 28: 357-365.

Jung, R. E., Philipp, A., Annen, B. M., Signorelli, L., Thoma, D. S., Hammerle, C. H., Attin, T. \& Schmidlin, P. (2013b) Radiographic evaluation of different techniques for ridge preservation after tooth extraction: A randomized controlled clinical trial. Journal of Clinical Periodontology 40: 90-98.

Jung, R. E., Sailer, I., Hammerle, C. H., Attin, T. \& Schmidlin, P. (2007) In vitro color changes of soft tissues caused by restorative materials. International Journal of Periodontics and Restorative Dentistry 27: 251-257.

Jung, R. E., Zembic, A., Pjetursson, B. E., Zwahlen, M. \& Thoma, D. S. (2012) Systematic review of the survival rate and the incidence of biological, technical, and aesthetic complications of single crowns on implants reported in longitudinal studies with a mean follow-up of 5 years. Clinical Oral Implants Research 23 Suppl 6: 2-21.

Kalender, W. A., Hebel, R. \& Ebersberger, J. (1987) Reduction of ct artifacts caused by metallic implants. Radiology 164: 576-577.

Kamburoglu, K., Kolsuz, E., Murat, S., Eren, H., Yuksel, S. \& Paksoy, C. S. (2013) Assessment of buccal marginal alveolar peri-implant and periodontal defects using a cone beam ct system with and without the application of metal artefact reduction mode. Dento-Maxillo-Facial Radiology 42: 20130176.

Kamburoglu, K., Murat, S., Kilic, C., Yuksel, S., Avsever, H., Farman, A. \& Scarfe, W. C. (2014) Accuracy of cbct images in the assessment of buccal marginal alveolar peri-implant defects: Effect of field of view. Dento-Maxillo-Facial Radiology 43: 20130332.

Kaminaka, A., Nakano, T., Ono, S., Kato, T. \& Yatani, H. (2014) Cone-beam computed tomography evaluation of horizontal and vertical dimensional changes in buccal peri-implant alveolar bone and soft tissue: A 1-year prospective clinical study. Clinical Implant Dentistry and Related Research.

Karl, M., Winter, W., Taylor, T. D. \& Heckmann, S. M. (2004) In vitro study on passive fit in implant-supported 5-unit fixed partial dentures. International Journal of Oral and Maxillofacial Implants 19: 30-37. 
Kehl, M., Swierkot, K. \& Mengel, R. (2011) Three-dimensional measurement of bone loss at implants in patients with periodontal disease. Journal of Periodontology 82: 689-699.

Kikuchi, K., Akiba, N., Sadr, A., Sumi, Y., Tagami, J. \& Minakuchi, S. (2014) Evaluation of the marginal fit at implant-abutment interface by optical coherence tomography. J Biomed Opt 19: 055002.

Klinke, T., Daboul, A., Maron, J., Gredes, T., Puls, R., Jaghsi, A. \& Biffar, R. (2012) Artifacts in magnetic resonance imaging and computed tomography caused by dental materials. PLoS One 7: e31766.

Koutouzis, T., Neiva, R., Nair, M., Nonhoff, J. \& Lundgren, T. (2014) Cone beam computed tomographic evaluation of implants with platform-switched morse taper connection with the implant-abutment interface at different levels in relation to the alveolar crest. International Journal of Oral and Maxillofacial Implants 29: 1157-1163.

Kuehni, R. G. \& Marcus, R. T. (1979) An experiment in visual scaling of small color differences. Color Research \& Application 4: 83-91.

Lang, N. P., Zitzmann, N. U. \& Working Group 3 of the, V. E. W. o. P. (2012) Clinical research in implant dentistry: Evaluation of implant-supported restorations, aesthetic and patient-reported outcomes. Journal of Clinical Periodontology 39 Suppl 12: 133138.

Lemes, H. D., Sartori, I. A., Cardoso, L. C. \& Ponzoni, D. (2014) Behaviour of the buccal crestal bone levels after immediate placement of implants subjected to immediate loading. International Journal of Oral and Maxillofacial Surgery.

Miyamoto, Y. \& Obama, T. (2011) Dental cone beam computed tomography analyses of postoperative labial bone thickness in maxillary anterior implants: Comparing immediate and delayed implant placement. International Journal of Periodontics and Restorative Dentistry 31: 215-225.

Modder, U., Steinbrich, W., Heindel, W., Lindemann, J. \& Brusis, T. (1985) [indications for nuclear magnetic resonance tomography in tumors of the facial skeleton and neck area]. Digitale Bilddiagnostik 5: 55-60.

Mounir, M., Beheiri, G. \& El-Beialy, W. (2014) Assessment of marginal bone loss using full thickness versus partial thickness flaps for alveolar ridge splitting and immediate implant placement in the anterior maxilla. International Journal of Oral and Maxillofacial Surgery 43: 1373-1380.

Muller, H. P., Schaller, N. \& Eger, T. (1999) Ultrasonic determination of thickness of masticatory mucosa: A methodologic study. Oral Surgery, Oral Medicine, Oral Pathology, Oral Radiology and Endodontics 88: 248-253.

Nackaerts, O., Maes, F., Yan, H., Couto Souza, P., Pauwels, R. \& Jacobs, R. (2011) Analysis of intensity variability in multislice and cone beam computed tomography. Clinical Oral Implants Research 22: 873-879. 
Naitoh, M., Hayashi, H., Tsukamoto, N. \& Ariji, E. (2012) Labial bone assessment surrounding dental implant using cone-beam computed tomography: An in vitro study. Clinical Oral Implants Research 23: 970-974.

Nogueira-Filho, G., Xiang, X. M., Shibli, J. A., Duarte, P. M., Sowa, M. G., Ferrari, D. S., Onuma, T., de Cardoso, L. A. \& Liu, K. Z. (2011) On site noninvasive assessment of peri-implant inflammation by optical spectroscopy. Journal of Periodontal Research 46: 382-388.

Otis, L. L., Everett, M. J., Sathyam, U. S. \& Colston, B. W., Jr. (2000) Optical coherence tomography: A new imaging technology for dentistry. Journal of the American Dental Association 131: 511-514.

Pang, C., Ding, Y., Zhou, H., Qin, R., Hou, R., Zhang, G. \& Hu, K. (2014) Alveolar ridge preservation with deproteinized bovine bone graft and collagen membrane and delayed implants. Journal of Craniofacial Surgery 25: 1698-1702.

Paniz, G., Bressan, E., Stellini, E., Romeo, E. \& Lops, D. (2014) Correlation between subjective and objective evaluation of peri-implant soft tissue color. Clinical Oral Implants Research 25: 992-996.

Papaspyridakos, P., Benic, G. I., Hogsett, V. L., White, G. S., Lal, K. \& Gallucci, G. O. (2012) Accuracy of implant casts generated with splinted and non-splinted impression techniques for edentulous patients: An optical scanning study. Clinical Oral Implants Research 23: 676-681.

Park, S. E., Da Silva, J. D., Weber, H. P. \& Ishikawa-Nagai, S. (2007) Optical phenomenon of peri-implant soft tissue. Part i. Spectrophotometric assessment of natural tooth gingiva and peri-implant mucosa. Clinical Oral Implants Research 18: 569-574.

Parsa, A., Ibrahim, N., Hassan, B., Syriopoulos, K. \& van der Stelt, P. (2014) Assessment of metal artefact reduction around dental titanium implants in cone beam ct. Dento-Maxillo-Facial Radiology 43: 20140019.

Pauwels, R., Jacobs, R., Singer, S. R. \& Mupparapu, M. (2015) Cbct-based bone quality assessment: Are hounsfield units applicable? Dento-Maxillo-Facial Radiology 44: 20140238.

Pauwels, R., Stamatakis, H., Bosmans, H., Bogaerts, R., Jacobs, R., Horner, K., Tsiklakis, K. \& Consortium, S. P. (2013) Quantification of metal artifacts on cone beam computed tomography images. Clinical Oral Implants Research 24 Suppl A100: 94-99.

Pecnik, C. M., Roos, M., Muff, D., Spolenak, R. \& Sailer, I. (2014) In vitro color evaluation of esthetic coatings for metallic dental implants and implant prosthetic appliances. Clinical Oral Implants Research.

Pjetursson, B. E., Thoma, D., Jung, R., Zwahlen, M. \& Zembic, A. (2012a) A systematic review of the survival and complication rates of implant-supported fixed 
dental prostheses (fdps) after a mean observation period of at least 5 years. Clinical Oral Implants Research 23 Suppl 6: 22-38.

Pjetursson, B. E., Zwahlen, M. \& Lang, N. P. (2012b) Quality of reporting of clinical studies to assess and compare performance of implant-supported restorations. Journal of Clinical Periodontology 39 Suppl 12: 139-159.

Pompa, V., Galasso, S., Cassetta, M., Pompa, G., De Angelis, F. \& Di Carlo, S. (2010) A comparative study of magnetic resonance (mr) and computed tomography (ct) in the pre-implant evaluation. Annali di Stomatologia 1: 33-38.

Razavi, T., Palmer, R. M., Davies, J., Wilson, R. \& Palmer, P. J. (2010) Accuracy of measuring the cortical bone thickness adjacent to dental implants using cone beam computed tomography. Clinical Oral Implants Research 21: 718-725.

Ritter, L., Elger, M. C., Rothamel, D., Fienitz, T., Zinser, M., Schwarz, F. \& Zoller, J. E. (2014) Accuracy of peri-implant bone evaluation using cone beam ct, digital intraoral radiographs and histology. Dento-Maxillo-Facial Radiology 43: 20130088.

Roe, P., Kan, J. Y., Rungcharassaeng, K., Caruso, J. M., Zimmerman, G. \& Mesquida, J. (2012) Horizontal and vertical dimensional changes of peri-implant facial bone following immediate placement and provisionalization of maxillary anterior single implants: A 1-year cone beam computed tomography study. International Journal of Oral and Maxillofacial Implants 27: 393-400.

Rossi, F., Romanelli, P., Ricci, E., Marchetti, C. \& Botticelli, D. (2013) A cone beam tomographic evaluation of hard tissue alterations at immediate implants: A clinical prospective study. International Journal of Periodontics and Restorative Dentistry 33: 815-823.

Sailer, I., Fehmer, V., Ioannidis, A., Hammerle, C. H. \& Thoma, D. S. (2014) Threshold value for the perception of color changes of human gingiva. International Journal of Periodontics and Restorative Dentistry 34: 757-762.

Sailer, I., Zembic, A., Jung, R. E., Siegenthaler, D., Holderegger, C. \& Hammerle, C. H. (2009) Randomized controlled clinical trial of customized zirconia and titanium implant abutments for canine and posterior single-tooth implant reconstructions: Preliminary results at 1 year of function. Clinical Oral Implants Research 20: 219-225.

Salmon, B. \& Le Denmat, D. (2012) Intraoral ultrasonography: Development of a specific high-frequency probe and clinical pilot study. Clinical Oral Investigations 16: 643-649.

Sancho-Puchades, M., Hammerle, C. H. \& Benic, G. I. (2014) In vitro assessment of artifacts induced by titanium, titanium-zirconium and zirconium dioxide implants in cone-beam computed tomography. Clinical Oral Implants Research.

Sbordone, C., Toti, P., Guidetti, F., Califano, L., Bufo, P. \& Sbordone, L. (2013) Volume changes of autogenous bone after sinus lifting and grafting procedures: A 6year computerized tomographic follow-up. Journal of Cranio-Maxillo-Facial Surgery 41: 235-241. 
Schneider, D., Grunder, U., Ender, A., Hammerle, C. H. \& Jung, R. E. (2011) Volume gain and stability of peri-implant tissue following bone and soft tissue augmentation: 1-year results from a prospective cohort study. Clinical Oral Implants Research 22: 28-37.

Schneider, D., Schmidlin, P. R., Philipp, A., Annen, B. M., Ronay, V., Hammerle, C. H., Attin, T. \& Jung, R. E. (2014) Labial soft tissue volume evaluation of different techniques for ridge preservation after tooth extraction: A randomized controlled clinical trial. Journal of Clinical Periodontology 41: 612-617.

Schropp, L., Wenzel, A., Spin-Neto, R. \& Stavropoulos, A. (2014) Fate of the buccal bone at implants placed early, delayed, or late after tooth extraction analyzed by cone beam ct: 10 -year results from a randomized, controlled, clinical study. Clinical Oral Implants Research.

Schulze, R., Heil, U., Gross, D., Bruellmann, D. D., Dranischnikow, E., Schwanecke, U. \& Schoemer, E. (2011) Artefacts in cbct: A review. Dento-Maxillo-Facial Radiology 40: 265-273.

Schulze, R. K., Berndt, D. \& d'Hoedt, B. (2010) On cone-beam computed tomography artifacts induced by titanium implants. Clinical Oral Implants Research 21: 100-107.

Senel, F. C., Duran, S., Icten, O., Izbudak, I. \& Cizmeci, F. (2006) Assessment of the sinus lift operation by magnetic resonance imaging. British Journal of Oral and Maxillofacial Surgery 44: 511-514.

Shiratori, L. N., Marotti, J., Yamanouchi, J., Chilvarquer, I., Contin, I. \& TortamanoNeto, P. (2012) Measurement of buccal bone volume of dental implants by means of cone-beam computed tomography. Clinical Oral Implants Research 23: 797-804.

Smedberg, J. I., Nilner, K., Rangert, B., Svensson, S. A. \& Glantz, S. A. (1996) On the influence of superstructure connection on implant preload: A methodological and clinical study. Clinical Oral Implants Research 7: 55-63.

Sowa, M. G., Leonardi, L., Payette, J. R., Cross, K. M., Gomez, M. \& Fish, J. S. (2006) Classification of burn injuries using near-infrared spectroscopy. J Biomed Opt 11: 054002.

Sowa, M. G., Leonardi, L., Payette, J. R., Fish, J. S. \& Mantsch, H. H. (2001) Near infrared spectroscopic assessment of hemodynamic changes in the early post-burn period. Burns 27: 241-249.

Starcukova, J., Starcuk, Z., Jr., Hubalkova, H. \& Linetskiy, I. (2008) Magnetic susceptibility and electrical conductivity of metallic dental materials and their impact on mr imaging artifacts. Dental Materials 24: 715-723.

Stoetzer, M., Wagner, M. E., Wenzel, D., Lindhorst, D., Gellrich, N. C. \& von See, C. (2014) Nonradiological method for 3-dimensional implant position assessment using 
an intraoral scan: New method for postoperative implant control. Implant Dentistry 23: 612-616.

Tahmaseb, A., Wismeijer, D., Coucke, W. \& Derksen, W. (2014) Computer technology applications in surgical implant dentistry: A systematic review. International Journal of Oral and Maxillofacial Implants 29 Suppl: 25-42.

Tanaka, R., Hayashi, T., Ike, M., Noto, Y. \& Goto, T. K. (2013) Reduction of darkband-like metal artifacts caused by dental implant bodies using hypothetical monoenergetic imaging after dual-energy computed tomography. Oral Surg Oral Med Oral Pathol Oral Radiol 115: 833-838.

Tonetti, M., Palmer, R. \& Working Group 2 of the, V. E. W. o. P. (2012) Clinical research in implant dentistry: Study design, reporting and outcome measurements: Consensus report of working group 2 of the viii european workshop on periodontology. Journal of Clinical Periodontology 39 Suppl 12: 73-80.

Tsai, C. Y., Garaicoa-Pazmino, C., Mori, K., Benavides, E., Kaigler, D. \& Kapila, Y. (2014) Implant success remains high despite grafting voids in the maxillary sinus. Clinical Oral Implants Research.

Tymofiyeva, O., Vaegler, S., Rottner, K., Boldt, J., Hopfgartner, A. J., Proff, P. C., Richter, E. J. \& Jakob, P. M. (2013) Influence of dental materials on dental mri. Dento-Maxillo-Facial Radiology 42: 20120271.

van Brakel, R., Noordmans, H. J., Frenken, J., de Roode, R., de Wit, G. C. \& Cune, M. S. (2011) The effect of zirconia and titanium implant abutments on light reflection of the supporting soft tissues. Clinical Oral Implants Research 22: 1172-1178.

van der Meer, W. J., Andriessen, F. S., Wismeijer, D. \& Ren, Y. (2012) Application of intra-oral dental scanners in the digital workflow of implantology. PLoS One 7: e43312.

Vera, C., De Kok, I. J., Chen, W., Reside, G., Tyndall, D. \& Cooper, L. F. (2012) Evaluation of post-implant buccal bone resorption using cone beam computed tomography: A clinical pilot study. International Journal of Oral and Maxillofacial Implants 27: 1249-1257.

Verdugo, F., Simonian, K., Frydman, A., D'Addona, A. \& Ponton, J. (2011) Long-term block graft stability in thin periodontal biotype patients: A clinical and tomographic study. International Journal of Oral and Maxillofacial Implants 26: 325-332.

von See, C., Wagner, M. E., Schumann, P., Lindhorst, D., Gellrich, N. C. \& Stoetzer, M. (2014) Non-radiological method for three-dimensional implant position evaluation using an intraoral scan method. Clinical Oral Implants Research 25: 1091-1093.

Yilmaz, B., Ozcelik, T. B. \& Wee, A. G. (2009) Effect of repeated firings on the color of opaque porcelain applied on different dental alloys. Journal of Prosthetic Dentistry 101: 395-404. 
Zhao, S., Robertson, D. D., Wang, G., Whiting, B. \& Bae, K. T. (2000) X-ray ct metal artifact reduction using wavelets: An application for imaging total hip prostheses.

IEEE Transactions on Medical Imaging 19: 1238-1247. 